\title{
HUBUNGAN STATUS SOSIAL EKONOMI DENGAN TINGKAT KONSUMSI FAST FOOD PADA REMAJA
}

\author{
Musparlin Halid $^{1}$ dan Toto Sudargo $^{2}$ \\ ${ }_{1}^{1}$ Magister Ilmu Kesehatan Masyarakat, Fakultas Kedokteran, Universitas Gadjah Mada \\ 2 Program Studi gizi dan Kesehatan, Fakultas Kedokteran, Universitas Gadjah Mada
}

\begin{abstract}
Modernization has brought negative impact to the public, including in adolescents directly or indirectly, that has directed the diversion a healthy diet. Adolescent are required to more selective in choosing food products consumed. Fast food is food containing high in calories, fat and low fibers. To know the relationship of socioeconomic status with fast food consumption levels among adolescents in Mataram city. The study was observational studies with cross sectional design. The samples as many as 373 students. Dependent variable was the consumption of fast food, and the independent variable was socioeconomic status. The instruments used were questionnaire and FFQ. Data analysis by means of descriptive, and Chi Square test $\left(\chi^{2}\right)$. Based on the duration per week, there was a relationship between socioeconomic status with the western fast food consumption levels ( $p$ $=0.00)$ and local fast food $(p=0.00)$. Moreover, adolescents with prosperous socioeconomic status have a higher consumption of fast food was very high with a duration of 1 time/week and 2 times/week. While based on the frequency, there was a significant relationship between socioeconomic status with western fast food consumption levels with $p=0.00$ and local fast food with $p=0.00$ influence of friends was significant with western fast food consumption levels in adolescents $(p=0.002)$. The habit of eating at home (lunch with $p=0.007$ ) and the effect of mass media was significant with the local fast food consumption levels ( $p=0.04)$. Adolescents with a prosperous socioeconomic status have greater opportunities to consume fast food than in adolescents with socioeconomic status were less prosperous.
\end{abstract}

Keywords: Socioeconomic status, Fast food 


\section{PENDAHULUAN}

Modernisasi telah membawa pengaruh negatif kepada masyarakat termasuk pada remaja secara langsung maupun tidak langsung yang telah mengarahkan terjadinya penyimpangan pola makan yang sehat termasuk dalam hal ini peningkatan konsumsi makanan tinggi kalori, tinggi lemak dan rendah serat makanan yang mengandung kepadatan energi (gula) dan terjadi penurunan aktivitas fisik terutama daerah perkotaan.

Beberapa faktor yang mempengaruhi remaja dalam mengkonsumsi makanan sehari-hari terdiri dari faktor individu, lingkungan dan makrosistem. Pengaruh individu atau intrapersonal, misalnya psikososial, biologi, lingkungan sosial atau antar pribadi, misalnya keluarga dan teman sebaya, pengaturan lingkungan atau komunitas fisik, misalnya sekolah, keterpaparan lokasi restoran makanan cepat saji dan makro sistem atau masyarakat, misalnya media massa, pemasaran, periklanan, norma-norma sosial dan budaya.

Faktor psikososial dan lingkungan memainkan peran penting dalam pilihan makanan remaja dan ini meningkat menjadi pada masa dewasa muda.Selain itu, faktor status sosial ekonomi berhubungan positif dengan tingkat konsumsi makanan cepat saji meliputi status pernikahan, tingkat pendidikan, pendapatan, tingkat pekerjaan.Disamping itu, keluarga yang sering menyajikan fast food untuk anak remaja mereka, cenderung memiliki anak-anak remaja yang memiliki pola makan yang buruk dibandingkan dengan keluarga yang jarang atau tidak menyajikan fast food untuk anak remaja mereka.

Remaja merupakan kelompok yang rentan terhadap pola konsumsi makanan jenis fast food. Kepadatan energi yang tinggi, rendah kalsium, vitamin $\mathrm{C}$, vitamin $\mathrm{A}$, serat, tinggi kalori dan tinggi kolesterol pada makanan cepat saji mempengaruhi sistem kontrol nafsu makan pada manusia untuk selalu mengkonsumsinya sehingga dapat merubah kondisi tubuh yang tidak normal dan akan berpeluang menimbulkan penyakit degeneratif. 
Tujuan penelitian ini, untuk mengetahui hubungan status sosial ekonomi dengan tingkat konsumsi fast food pada remaja di Kota Mataram.

\section{METODE PENELITIAN}

Jenis penelitian yang digunakan dalam penelitian ini adalah studi observasional dengan rancangan cross sectional yang dilakukan beberapa Sekolah Menengah Atas (SMA) di Kota Mataram, yaitu SMAN 1 Mataram, SMAN 2 Mataram, SMAN 3 Mataram dan SMAN 5 Mataram dan dilaksanakan pada bulan April - Mei 2014.Subyek penelitian ini adalah siswa-siswi SMA yang ada di Kota Mataram.

Sampel penelitian sebesar 373 siswa yang diambil dengan teknik purposive sampling/judgmental sampling.Variabel dependen yaitu tingkat konsumsi fast food, dan variabel independen yaitu status sosial ekonomi. Sedangkan, variabel luar adalah pengaruh media massa, pengaruh teman sebaya, kebiasaan makan makanan rumah dan jenis kelamin.

Instrumen yang digunakan adalah Food Frequency Questionnaire (FFQ) dan kuesioner.Analisis penelitian menggunakan uji chi-square $\left(\chi^{2}\right)$ dengan taraf signifikan $P<0$.05.Sedangkan untuk mengetahui kekuatan hubungan antara variabel dilakukan dengan melihat Rasio Prevalensi (RP) dengan Confidence Interval (CI 95\%).

Setelah data yang diperoleh dari hasil pengisian kuesioner, selanjutnya data tersebut akan dimasukkan ke dalam aplikasi Microsoft Office Exel. Kemudian data tersebut ditransfer ke software SPSS Versi 20 untuk diberikan label dan kode dan setelah itu, data ditransfer lagi ke software Stata Versi 12.

\section{HASIL}

Gambaran subyek penelitian dilakukan untuk melihat gambaran karakteristik dari masing-masing responden berdasarkan 
variabel-variabel tertentu dengan menggunakan distribusi frekuensi.

\section{Tabel 2}

Distribusi Karakteristik Responden

\begin{tabular}{|c|c|c|c|}
\hline $\begin{array}{l}\mathrm{N} \\
\mathrm{o} .\end{array}$ & Variabel & \multicolumn{2}{|c|}{$\begin{array}{c}n=373 \\
\%\end{array}$} \\
\hline \multirow[t]{3}{*}{1.} & Jenis kelamin & & \\
\hline & Laki-laki & 134 & 35.92 \\
\hline & Perempuan & 239 & 64.08 \\
\hline \multirow[t]{3}{*}{2.} & Umur & & \\
\hline & 15-16 tahun & 136 & 36.46 \\
\hline & 17-18 tahun & 237 & 63.54 \\
\hline \multirow[t]{3}{*}{3.} & Frekuensi Konsumsi Western Fast Food & & \\
\hline & Rendah & 26 & 6.97 \\
\hline & Sering & 347 & 93.03 \\
\hline \multirow[t]{3}{*}{4.} & Frekuensi Konsumsi Fast Food Lokal & & \\
\hline & Rendah & 64 & 17.16 \\
\hline & Sering & 309 & 82.84 \\
\hline \multirow[t]{5}{*}{5.} & \multicolumn{3}{|c|}{ Konsumsi Westernfast food berdasarkan durasi per minggu } \\
\hline & $1 \mathrm{kali} / \mathrm{minggu}$ & 185 & 49.60 \\
\hline & 2 kali/minggu & 106 & 28.42 \\
\hline & $\geq 3 \mathrm{kali} / \mathrm{minggu}$ & 56 & 15.01 \\
\hline & Tidak pernah & 26 & 6.97 \\
\hline \multirow[t]{5}{*}{6.} & \multicolumn{3}{|c|}{ Konsumsi fast food Lokal berdasarkan durasi per minggu } \\
\hline & $1 \mathrm{kali} / \mathrm{minggu}$ & 82 & 21.98 \\
\hline & $2 \mathrm{kali} / \mathrm{minggu}$ & 149 & 39.95 \\
\hline & $\geq 3 \mathrm{kali} / \mathrm{minggu}$ & 78 & 20.91 \\
\hline & Tidak pernah & 64 & 17.16 \\
\hline \multirow[t]{3}{*}{7.} & \multicolumn{3}{|l|}{ Status Sosial Ekonomi } \\
\hline & Sejahtera & 298 & 79.89 \\
\hline & Kurang sejahtera & 75 & 20.11 \\
\hline \multirow[t]{3}{*}{8.} & Kebiasaan Makan Makanan Rumah & & \\
\hline & a. Sarapan & & \\
\hline & Sering & 228 & 61.13 \\
\hline
\end{tabular}




\begin{tabular}{|l|c|r|r|}
\hline & Jarang & 145 & 38.87 \\
\hline & b. Makan Siang & & \\
\hline & Sering & 330 & 88.47 \\
\hline & Jarang & 43 & 11.53 \\
\hline
\end{tabular}

Keterangan: $\mathrm{n}=$ Jumlah responden

Berdasarkan hasil analisis pada Tabel 1, memperlihatkan persentase jenis kelamin perempuan lebih banyak sebesar $64.08 \%$ dan kebanyakan responden berumur 17-18 tahun dengan persentase sebesar $63.54 \%$. Frekuensi konsumsi makanan cepat saji western pada remaja sangat tinggi dengan proporsi sebesar 93.03\% dan fast food lokal sebesar $82.84 \%$ dari total keseluruhan responden. Responden lebih dominan mengkonsumsi western fast food dengan durasi $1 \mathrm{kali} / \mathrm{minggu}$ (49.60\%) dan fast food lokal dengan durasi 2 kali/minggu (39.95\%).Rata-rata responden mempunyai status sosial ekonomi keluarga dengan kategori keluarga sejahtera (79.89\%).

Hasil penelitian menunjukkan bahwa responden lebih sering mempunyai kebiasaan makan di rumah meliputi sarapan, makan siang dan makan malam masing-masing sebesar 79.89\%, 88.47\% dan 86.60\%. Responden memperlihatkan lebih banyak terpengaruh teman sebaya dalam mengkonsumsi fast food sebesar 95.44\% terpengaruh oleh media massa (51.21\%).

Variasi jenis westernfast food yang dikonsumsi responden lebih banyak mengkonsumsi $>5$ jenis (tinggi) sebesar 65.68\%.Untuk fast food lokal, responden lebih banyak mengkonsumsi fast food $<5$ jenis (rendah) sekitar 64.88\% (Tabel 2).

Tabel 1

Distribusi Frekuensi Responden Mengkonsumsi WesternFast Food dan Fast Food Lokal selama 1 Bulan Terakhir

\begin{tabular}{|c|c|c|}
\hline Variabel & $\mathrm{n}=373$ & $\%$ \\
\hline \multicolumn{3}{|c|}{ Variasi Konsumsi WesternFast Food } \\
\hline Rendah & 128 & 34.32 \\
\hline Tinggi & 245 & 65.68 \\
\hline
\end{tabular}

78 BIOTA: Jurnal Tadris IPA Biologi FITK IAIN Mataram 


\begin{tabular}{|c|c|c|}
\hline \multicolumn{3}{|l|}{ Variasi Konsumsi Fast Food Lokal } \\
\hline Rendah & 242 & 64.88 \\
\hline Tinggi & 131 & 35.12 \\
\hline
\end{tabular}

Keterangan: $\mathrm{n}=$ Jumlah responden

\section{Tabel 2}

Hubungan Status Sosial Ekonomi dengan Tingkat Konsumsi WesternFast Food Berdasarkan Durasi per Minggu pada Remaja

\begin{tabular}{|c|c|c|c|c|c|c|c|}
\hline \multirow{4}{*}{ Variabel } & \multicolumn{4}{|c|}{ Western FastFood } & \multirow{4}{*}{$\chi^{2}$} & \multirow{4}{*}{$p$} & \multirow{4}{*}{$\begin{array}{c}\mathrm{RP} \\
\text { CI 95\% }\end{array}$} \\
\hline & $1 \mathrm{x} / \mathrm{m}$ & $2 \mathrm{x} / \mathrm{m}$ & $\geq 3 \mathrm{x} / \mathrm{m}$ & $\mathrm{TP}$ & & & \\
\hline & $\mathrm{n}$ & $\mathrm{n}$ & $\mathrm{n}$ & $\mathrm{n}$ & & & \\
\hline & $\%$ & $\%$ & $\%$ & $\%$ & & & \\
\hline \multicolumn{5}{|c|}{ Status Sosial Ekonomi } & \multirow{5}{*}{20.2} & \multirow{5}{*}{$0.00 *$} & \multirow{5}{*}{$\begin{array}{c}1.07 \\
0.84-1.36\end{array}$} \\
\hline \multirow[t]{2}{*}{ Sejahtera } & 150 & 89 & 47 & 12 & & & \\
\hline & 50.34 & 29.87 & 15.77 & 4.03 & & & \\
\hline \multirow{2}{*}{$\begin{array}{l}\text { Kurang } \\
\text { sejahtera }\end{array}$} & 35 & 17 & 9 & 14 & & & \\
\hline & 46.67 & 22.67 & 12 & 18.67 & & & \\
\hline
\end{tabular}

Keterangan:

$\begin{array}{lll}\chi^{2}=\text { Chi- } & \mathrm{RP}=\text { Rasio Prevalensi } & *=\text { Signifikan } \\ \text { Square } & \text { CI 95\%=Confidence Interval } & \mathrm{TP}=\text { Tidak } \\ p=p \text {-value } & 95 \% & \text { pernah }\end{array}$

Tabel 3, menunjukkan terdapat hubungan yang signifikan antara status sosial ekonomi dengan frekuensi konsumsi westernfast food ( $p=0.00 ; \mathrm{RP}=1.07$ dan CI 95\%=0.84-1.36). Dengan demikian, remaja dengan status sosial ekonomi sejahtera (50.34\%) mempunyai peluang sebesar 1.07 kali untuk mengkonsumsi fast food.

\section{Hubungan antara Status Sosial Ekonomi dengan Frekuensi Konsumsi Fast Food}

Berdasarkan hasil analisis statistik membuktikan bahwa terdapat hubungan yang signifikan antara kondisi status sosial ekonomi keluarga dengan frekuensi konsumsi westernfast food maupun fast food lokal $(p<0.05)$. Berdasarkan durasi konsumsi 
per minggu, remaja dengan status sosial ekonomi sejahtera mempunyai peluang sebesar 1.07 kali untuk mengkonsumsi fast food.Selain itu, remaja dengan status sosial ekonomi sejahtera mempunyai frekuensi lebih tinggi (50.34\%) untuk mengkonsumsi fast food dengan durasi $1 \mathrm{kali} /$ minggu.

Sedangkan berdasarkan frekuensinya, remaja dengan status sosial ekonomi sejahtera mempunyai peluang 6.35 kali untuk mengkonsumsi fastfood dibandingkan dengan keluarga yang kurang sejahtera.Remaja yang mengkonsumsi fast food mempunyai frekuensi sangat tinggi sebesar $96.64 \%$ dari golongan keluarga yang sejahtera.Hal tersebut, sejalan dengan hasil penelitian lainnya memaparkan bahwa terdapat hubungan yang signifikan $(p<0.05)$ antara keadaan status sosial ekonomi keluarga dengan tingkat konsumsi fast food selama $\geq 1$ kali/minggu pada siswa.

Menurut Evans et al. menjelaskan bahwa keluarga yang sejahtera lebih sering mengkonsumsi fast food dibandingkan dengan keluarga yang kurang sejahtera, serta terdapat hubungan yang kompleks dengan akses untuk mengunjungi restauran makanan cepat saji. Fast food dapat menyebabkan risiko terhadap status kesehatan individu, seperti obesitas, cardiovascular disease dan diabetes.

\section{Hubungan antara Jenis Kelamin dengan Tingkat Konsumsi Fast Food}

Hasil analisis statistik membuktikan bahwa tidak terdapat hubungan yang signifikan antara jenis kelamin dengan frekuensi konsumsi western fast food maupun fast food lokal $(p>0.05)$ pada remaja di Kota Mataram. Namun, frekuensi remaja yang mengkonsumsi western fast food sangat tinggi pada remaja perempuan sebesar $53.56 \%$ dengan durasi $1 \mathrm{kali} / \mathrm{minggu}$ dan pada fast food lokal sebesar $40.17 \%$ dengan durasi $2 \mathrm{kali} / \mathrm{minggu}$.

Serupa dengan hasil penelitian lainnya menjelaskan bahwa negatif ditemukan hubungan yang signifikan. Selain itu, responden yang mengkonsumsi makanan cepat saji cukup tinggi 
berdasarkan jenis kelamin dengan durasi konsumsi $\geq 3-4$ $\mathrm{kali} / \operatorname{minggu}^{(5,15,20)}$.

\section{Hubungan antara Kebiasaan Makan di Rumah dengan Tingkat Konsumsi Fast Food}

Hasil analisis statistik pada penelitian ini memaparkan bahwa tidak ada hubungan yang signifikan antara kebiasaan makan makanan rumha dengan tingkat konsumsi western fast food $(p>0.05)$.Terdapat hubungan yang signifikan antara kebiasaan makan makanan rumah (makan siang) dengan tingkat konsumsi fastfood lokal $(p<0.05)$, namun tidak pada kebiasaan sarapan dan makan malam ( $p>0.05)$.Remaja yang mempunyai kebiasaan makan siang di rumah dapat mengurangi peluang sebesar 0.78 kali untuk mengkonsumsi fast food lokal.

Penelitian ini sejalan dengan hasil penelitian lainnya yang menjelaskan bahwa yang mempunyai kebiasaan makan siang di rumah yang kurang baik mempunyai peluang untuk mengkonsumsi fast food dengan durasi 1-2 kali/minggu dan $\geq 3$ $\mathrm{kali} /$ minggu.

\section{Hubungan antara Pengaruh Teman Sebaya dengan Tingkat Konsumsi Fast Food}

Berdasarkan hasil uji statistik menjelaskan bahwa terdapat hubungan yang signifikan antara pengaruh teman sebaya dengan frekuensi konsumsi western fast food pada remaja di Kota Mataram $(p<0.05)$.Remaja yang terpengaruh oleh teman sebaya mempunyai peluang sebesar 1.30 kali untuk mengkonsumsi fast food.Remaja yang terpengaruh oleh teman sebaya mempunyai frekuensi lebih tinggi (50.28\%) dalam mengkonsumsi fastfood dengan durasi $1 \mathrm{kali} /$ minggu.Penelitian ini sejalan dengan hasil penelitian lainnya yang mengungkapkan bahwa pengaruh teman merupakan salah satu faktor yang menentukan tingkat konsumsi fast food. 
Berbeda antara hasil analisis membuktikan tidak terdapat hubungan yang signifikan antara pengaruh teman sebaya dengan frekuensi konsumsi fast food lokal pada remaja di Kota Mataram $(p>0.05)$. Hasil survei lainnya mengungkapkan bahwa responden cenderung sering mengkonsumsi makanan cepat saji $(\geq 3$ kali/minggu) didasari terhadap kurangnya perhatian dari teman terhadap dirinya tentang makan sehat $(10,22,27)$. Sumber utama informasi diet adalah siswa sendiri, orang tua, teman-teman, guru sekolah dan ahli gizi.

\section{Hubungan antara Pengaruh Media Massa dengan Tingkat Konsumsi Fast Food}

Berdasarkan hasil uji statistik pada penelitian ini menemukan bahwa tidak terdapat hubungan yang signifikan antara pengaruh media massa dengan tingkat konsumsi westernfast food $(p>0.05)$. Ditemukan hubungan antara pengaruh media massa dengan tingkat konsumsi fast food lokal pada remaja di Kota Mataram $(p<0.05)$. Remaja yang terpengaruh media massa mempunyai peluang 1.01 kali untuk mengkonsumsi fast food lokal.

Media massa merupakan faktor yang menentukan tingkat konsumsi fastfood pada remaja. Remaja merupakan target utama dari periklanan dalam promosi makanan cepat saji, makanan ringan dan minuman manis yang dapat mempengaruhi perilaku pemilihan makanan yang baik dan sehat. Media yang paling sering digunakan sebagai sumber informasi gizi termasuk tentang makanan cepat saji, yaitu televisi, internet, majalah atau koran, papan buletin yang ada di kantin sekolah.

\section{PENUTUP}

\section{Kesimpulan}

Berdasarkan hasil analisis statistik dan pembahasan dalam penelitian ini, menunjukkan bahwa ada hubungan antara status sosial ekonomi dengan tingkat konsumsi westernfast food maupun 
pada fast food lokal pada remaja di Kota Mataram.Remaja dengan status sosial ekonomi yang sejahtera mempunyai peluang lebih besar untuk mengkonsumsi fast food dari pada remaja dengan status sosial ekonomi kurang sejahtera. Selain itu, pengaruh teman sebaya berhubungan dengan tingkat konsumsi westernfast food, serta pengaruh media massa dan kebiasaan makan makanan rumah (makan siang) berhubungan dengan tingkat konsumsi fast food lokal pada remaja.

\section{DAFTAR PUSTAKA}

Adriani, Merryana \& Wirjatmadi, B. (2012).Peranan Gizi dalam Siklus Kehidupan (1st ed.). Jakarta: Kencana Prenada Media Group.

Akman, M., Akan, H., İzbirak, G., Tanrı̈ver, Ö., Tilev, S., Yıldız, A., Tektaş, S., et al. (2010). Eating patterns of Turkish adolescents: a cross-sectional survey.Nutrition Journal, 9(1), 67.

Almatsier, S., Soetardjo, S. \& Soekatri, M. (2011).Gizi Seimbang dalam Daur Kehidupan. Jakarta: PT. Gramedia Pustaka Utama.

Anderson, B., Rafferty, A. P., Lyon-Callo, S., Fussman, C., \& Imes, G. (2011).Fast-food consumption and obesity among Michigan adults.Preventing chronic disease, 8(4), A71.

Arcan, C., Kubik, M. Y., Fulkerson, J. A., \& Story, M. (2009). Sociodemographic differences in selected eating practices among alternative high school students. Journal of the American Dietetic Association, 109(5), 823-9.

Barr-Anderson, D. J., Larson, N. I., Nelson, M. C., Neumark-Sztainer, D., \& Story, M. (2009). Does television viewing predict dietary intake five years later in high school students and young adults? The international journal of behavioral nutrition and physical activity, 6, 7.

Bowman, S. A., Gortmaker, S. L., Ebbeling, C. B., Pereira, M. A., \& Ludwig, D. S. (2003). Effects of Fast-Food Consumption on 
Energy Intake and Diet Quality Among Children in a National Household Survey. PEDIATRICS, 113(1), 112-118. Dubé, L., Bechara, A., Dagher, A., Drewnowski, A., Lebel, J., James, P., \& Yada, R. Y. (2010).Obesity Prevention: The Role of Brain and Society on Individual Behavior (1st ed.). London: Academic Press.

French, S. a, Harnack, L., \& Jeffery, R. W. (2000). Fast food restaurant use among women in the Pound of Prevention study: dietary, behavioral and demographic correlates. International journal of obesity and related metabolic disorders : journal of the International Association for the Study of Obesity, 24(10), 1353-9.

Fulkerson, J. A., Kubik, M. Y., Story, M., Lytle, L., \& Arcan, C. (2009). Are there nutritional and other benefits associated with family meals among at-risk youth? The Journal of adolescent health : official publication of the Society for Adolescent Medicine, 45(4), 389-95.

Gordis, L. (2014). Epidemiology (5th ed.). Philadelphia: Saunders Elsevier.

Hadi, H. (2005). Beban Ganda Masalah Gizi dan Implikasinya terhadap Kebijakan Pembangunan Kesehatan Nasional.Pidato Pengukuhan Guru Besar pada Fakultas Kedokteran Universitas Gadjah Mada.Yogyakarta.

Jeffery, Robert W, Baxter, J., McGuire, M., \& Linde, J. (2006). Are fast food restaurants an environmental risk factor for obesity? The international journal of behavioral nutrition and physical activity, $3,2$.

Larson, N., Neumark-Sztainer, D., Laska, M. N., \& Story, M. (2011). Young adults and eating away from home: Associations with dietary intake patterns and weight status differ by choice of restaurant. Journal of the American Dietetic Association, 111(11), 1696-1703.

Moore, L. V., Diez Roux, A. V., Nettleton, J. a, Jacobs, D. R., \& Franco, M. (2009). Fast-food consumption, diet quality, and neighborhood exposure to fast food: the multi-ethnic study of atherosclerosis. American journal of epidemiology, 170(1), 29-36.

84 BIOTA: Jurnal Tadris IPA Biologi FITK IAIN Mataram 
Neumark-Sztainer, D., Hannan, P. J., Story, M., Croll, J., \& Perry, C. (2003). Family meal patterns: associations with sociodemographic characteristics and improved dietary intake among adolescents. Journal of the American Dietetic Association, 103(3), 317-22.

Prentice, A. M., \& Jebb, S. A. (2003). Fast foods, energy density and obesity: a possible mechanistic link. Obesity reviews : an official journal of the International Association for the Study of Obesity, 4(4), 187-94.

Satia, J., Galanko, J., \& Siega-Riz, A. (2004). Eating at fast-food restaurants is associated with dietary intake, demographic, psychosocial and behavioural factors among African Americans in North Carolina. Public health nutrition, 7(8), 1089-1096.

Seubsman, S.-A., Kelly, M., Yuthapornpinit, P., \& Sleigh, A. (2009).Cultural resistance to fast-food consumption?A study of youth in North Eastern Thailand.International journal of consumer studies, 33(6), 669-675.

Story, M., Neumark-Sztainer, D., \& French, S. (2002). Individual and environmental influences on adolescent eating behaviors.Journal of the American Dietetic Association, 102(3 Suppl), S40-51.

Voorhees, C., Catellier, D., Ashwood, J., Cohen, D., Rung, A., Lytie, L., Conwey, T., et al. (2009). Neighborhood socioeconomic status and non school physical activity and body mass index in adolescent girls. ... of physical activity \& ..., 6(6), 731-740.

Yoon, J.-Y., Lyu, E.-S., \& Lee, K.-A.(2008). Korean adolescents' perceptions of nutrition and health towards fast foods in Busan area.Nutrition research and practice, 2(3), 171-7. 